\title{
Insufficient tuberculosis treatment leads to earlier and higher mortality in individuals co-infected with HIV in southern China: a cohort study
}

Zhigang Zheng ${ }^{1,2+}$, Eric J. Nehl ${ }^{3 \dagger}$, Chongxing Zhou ${ }^{2}$, Jianjun $\mathrm{Li}^{2}$, Zhouhua Xie ${ }^{4}$, Zijun Zhou ${ }^{4}$ and Hao Liang ${ }^{5,6^{*}}$ (D)

\begin{abstract}
Background: Tuberculosis (TB) and Acquired Immune Deficiency Syndrome (AIDS) are leading causes of death globally. However, little is known about the long-term mortality risk and the timeline of death in those co-infected with human immunodeficiency virus (HIV) and Mycobacterium tuberculosis (MTB). This study sought to understand the long-term mortality risk, factors, and the timeline of death in those with HIV-Mycobacterium tuberculosis (MTB) coinfection, particularly in those with insufficient TB treatment.
\end{abstract}

Methods: TB-cause specific deaths were classified using a modified 'Coding of Cause of Death in HIV' protocol. A longitudinal cross-registration-system checking approach was used to confirm HIV/MTB co-infection between two observational cohorts. Mortality from the end of TB treatment (6 months) to post-treatment year (PTY) 5 (60 months) was investigated by different TB treatment outcomes. General linear models were used to estimate the mean mortality at each time-point and change between time-points. Cox's proportional hazard regressions measured the mortality hazard risk (HR) at each time-point. The Mantel-Haenszel stratification was used to identify mortality risk factors. Mortality density was calculated by person year of follow-up.

Results: At the end point, mortality among patients with HIV/MTB coinfection was 34.7\%. From the end of TB treatment to PTY5, mortality and loss of person years among individuals with TB treatment failure, missing, and adverse events (TBFMA) were significantly higher than those who had TB cure (TBC) and TB complete regimen (TBCR). Compared to individuals with TBC and with TBCR, individuals with TBFMA tended to die earlier and their mortality was significantly higher (HR $\mathrm{R}_{\mathrm{TBFMA}-\mathrm{TBC}}=3.0$, 95\% confidence interval: $2.5-3.6, \mathrm{HR}_{\mathrm{TBFMA}-\mathrm{TBCR}}=2.9,95 \%$ Cl: $2.5-$ $3.4, P<0.0001)$. Those who were naïve to antiretroviral therapy, were farmers, had lower CD4 counts ( $\leq 200 \mathrm{cell} s / \mu \mathrm{L})$ and were $\geq 50$ years of age were at the highest risk of mortality. Mortality risk for participants with TBFMA was significantly higher across all stratifications except those with a CD4 count of $\leq 200$ cells $/ \mu \mathrm{L}$.

Conclusions: Earlier and long-term mortality among those with HIV/MTB co-infection is a significant problem when TB treatment fails or is inadequate.

\footnotetext{
* Correspondence: lianghao@gxmu.edu.cn

${ }^{\dagger}$ Zhigang Zheng and Eric J. Nehl contributed equally to this work.

${ }^{5}$ Guangxi Key Laboratory of AIDS Prevention and Treatment, School of Public

Health, Guangxi Medical University, Nanning 530021, Guangxi, China

${ }^{6}$ Guangxi Collaborative Innovation Center for Biomedicine, Life Sciences

Institute, Guangxi Medical University, No.22, Shuangyong Road, Qingxiu

District, Nanning 530021, Guangxi, China

Full list of author information is available at the end of the article
}

(c) The Author(s). 2020 Open Access This article is licensed under a Creative Commons Attribution 4.0 International License, which permits use, sharing, adaptation, distribution and reproduction in any medium or format, as long as you give appropriate credit to the original author(s) and the source, provide a link to the Creative Commons licence, and indicate if changes were made. The images or other third party material in this article are included in the article's Creative Commons licence, unless indicated otherwise in a credit line to the material. If material is not included in the article's Creative Commons licence and your intended use is not permitted by statutory regulation or exceeds the permitted use, you will need to obtain permission directly from the copyright holder. To view a copy of this licence, visit http://creativecommons.org/licenses/by/4.0/ The Creative Commons Public Domain Dedication waiver (http://creativecommons.org/publicdomain/zero/1.0/) applies to the data made available in this article, unless otherwise stated in a credit line to the data. 


\section{Background}

Tuberculosis (TB) and Acquired Immune Deficiency Syndrome (AIDS) are leading causes of death globally. The World Health Organization (WHO) estimates that there were 10.4 million new cases of TB in 2016 and $10 \%$ of these people were co-infected with the human immunodeficiency virus (HIV). On its own, in the same year, it was estimated that there were 1.3 million TB deaths among HIV-negative people, with an additional 374,000 TB deaths among those HIV-positive. Additionally, among the 36.7 million people estimated to have been living with HIV worldwide [1], and 1 million who died from HIV-related causes, a full $40 \%$ were caused by TB in 2016 [2].

$\mathrm{HIV}$ infection increases the progression of latent $\mathrm{TB}$ infection to active TB disease [3] and accelerates TB disease [4]. Mycobacterium tuberculosis (MTB) infection increases the risk of progression from HIV to AIDS and death in HIV patients $[5,6]$. Improving treatment outcomes for antiretroviral therapy (ART) and antitubercular therapy are crucial for decreasing TB-related mortality among those with HIV/MTB co-infection. In 2010, WHO updated ART guidelines for HIV infection adults and adolescents, recommending that ART for all HIV-infected individuals with active TB, irrespective of their CD4 + T cell (CD4) count and that TB treatment should start first, followed by ART as quickly as possible afterward [7]. Following these guidelines, ART coverage improved rapidly worldwide; with $85 \%$ now on ART [1]. However, despite recommending ART and antitubercular therapy among patients presenting with TB and HIV, mortality associated with both diseases remains substantial [8] and the goal of halving TB-related deaths from 1990 levels by 2015 in high HIV/MTB coinfection prevalence countries has not been met.

China ranks in the top two of 22 high HIV/TB burden countries [1], and the overall prevalence of TB infection among those HIV positive is estimated to be $7.2 \%$ (range: 4.2-12.3\%) and is even higher (22.8\%) among AIDS patients [9]. Guangxi, a province of Southern China, bears the highest HIV/MTB burden in China, with 11\% TB prevalence among those with HIV and 3.3\% HIV prevalence among TB patients [9]. Furthermore, results of other research have shown that TB prevalence among those with HIV/AIDS was 17.7\% [10]. Although the latest treatment outcome data showed TB treatment success rates of $84 \%$ and ART initiation of $88 \%$ for those with HIV/TB coinfection in a 2015 cohort in China [1], the challenge of high mortality among those with HIV/MTB co-infection remains, with recent studies showing that most AIDS-related deaths were due to TB infection [10]. Specifically, over $19 \%$ of AIDSrelated deaths of those who were diagnosed and then died in the same calendar year in Guangxi have been attributed to TB [11]. However, little is known of the effects of TB treatment outcomes on long-term mortality of HIV/MTB co-infection globally. Insufficient TB treatment likely relates to ineffective TB infection control which leads to increases in mortality. But, the factors related to the high mortality among those with HIV/MTB coinfection who have initiated ART and anti-TB therapy have not been well described. Therefore, the goal of this study was to evaluate the impact of TB treatment outcomes on the long-term mortality of HIV/MTB coinfection, particularly in those who are with insufficient TB treatment.

\section{Materials and methods Study setting}

This study was carried out in Guangxi, Southern China. The number of HIV/MTB co-infection in this province constitutes more than $30 \%$ of the cases in China. Following international guidelines, in 2010 coordinated registration and care systems were initiated between the previously uncoordinated HIV and TB programs. Specifically, following WHO policies, those diagnosed with TB are tested for HIV and those initially diagnosed with HIV/AIDS are screened for TB annually in this province. Additionally, care services in Guangxi such as ART, anti-tubercular treatments, isoniazid preventive therapy, and infection control are now coordinated with the Chinese national HIV and TB programs.

\section{Study design and participants}

Patient data were considered for this study if they were 18 years or older and diagnosed with both HIV and MTB (including pulmonary TB and extra pulmonary TB). Their follow-up records were reviewed every 6 months to confirmed mortality in either HIV/AIDS or TB registration systems. Records were excluded when HIV or TB status was missing across registration systems and when patients listed their address to be overseas, Hong Kong, Macao, or Taiwan.

\section{Patient diagnosis and data collection}

Sequential screening strategies were used to prevent false positives for both MTB and HIV. For MTB, clinic doctors first took a chest X-ray (CXR), then three sputum samples or chest washing fluid samples were collected for smearing, Ziehl-Neelsen staining, and then microscopy was used to screen for MTB; samples were cultured for MTB if the smear was negative. MTB infection was diagnosed if acid-fast staining positive or positive isolation of culture was detected. For HIV, blood samples were collected and ELISA tests were used to test for HIV antibodies, followed by the western blot method to confirm HIV infection. 
Data collection: 14,293 unique patients were diagnosed and registered as being HIV/AIDS positive in 2011. We launched a cross-registration-systems check across the HIV treatment database, follow-up database, and registration database for MTB/HIV co-infection. Patients were classified as being co-infected with MTB/HIV if their TB infection status was confirmed in any of the three databases. We imputed the total MTB/HIV coinfection cases from HIV databases to the TB registration database, which included 42,205 TB cases, and obtained 2351 co-infection cases for analysis.

The 60-month (PTY5) follow-up period was calculated from the date of patient registration; for patients who died or were missing, the date of death or the date the patient was reported missing was considered the endpoint of the follow-up. Standard follow-up information was recorded by the program staff and reported via an Internet-based system, including patient ID, time of follow-up, CD4 count, WHO clinical disease stage, and adverse events. After the recommended treatment duration (6 months for cases of drugs-susceptible TB, and one and a half year or longer for drug resistant and extra pulmonary $\mathrm{TB}$ ) treatment outcomes were evaluated using sputum smear microscopy, CXR, and assessment of clinical symptoms. Patients were classified for this study according to these TB treatment outcomes including: TB cure (TBC) if they had completely recovered, TB complete regimen (TBCR) if they took their pills for the duration of the treatment period but did not recover completely, and $\mathrm{TB}$ treatment failure, missing, and adverse events (TBFMA) if they did not exhibit any improvement with their smear, had missing data, or reported experiencing adverse events. If a patient was lost to follow-up (3 months' absence from a clinic since last visit), a site visit of the participant's address was conducted by clinic staff to confirm their absence or death. Information collected at the site visits included the date of the last visit to the clinic or date of death.

\section{Statistical analyses}

Data Source: Data were stratified for analysis based upon literature related to the topic and preliminary bivariate analysis. Age, gender, ART status, CD4 count, occupation, ethnicity, and route of infection were used as stratification factors. To identify potential confounding factors, bivariate Mantel-Haenszel hierarchical analysis was used to calculate the odds risk (OR) for each stratification factor. Mortality was found to be not statistically different between TBC and TBCR groups, so TBC and TBCR groups were combined to compare to those with TBFMA. We then compared the OR values for stratification variables between TBFMA and TBC/TBCR group to identify confounding factors. Confounding factors were confirmed if the difference in OR values was found to be statistically significant between TBFMA and the TBC/TBCR groups.

Analysis indices: A general linear model for mortality measurements was used for each clinical time-point [6 months (end of TB treatment), 12 months (PTY1), 24 months (PTY2), 36 months (PTY3), 48 months (PTY4), and 60 months (PTY5)] to generate restricted maximum likelihood estimates. Mortality and mortality hazard risk were compared over the 60 month period using Cox regression models; a descriptive epidemiologic method was used to describe the characteristics; a chi-square test was used to compare the differences in demographic characteristics of TBC, TBRC, and TBFMA; and a hierarchical analysis method was used to identify confounding factors, as described above. Adjusted HR values were calculated by removing those who died within the initial 6 months of therapy; adjusted OR values were calculated across the selected subgroups (adjusted for age, gender, ART, CD4 count).

Data were analyzed with $\mathrm{R}$ (version 3.2.2, R Foundation for statistical Computing, Vienna, Austria) and SPSS 22.0, the significance level was set at 0.05 , and all hypothesis tests were two-sided.

\section{Results \\ Study subject characteristics}

Two thousand three fifty-one MTB/HIV co-infections were confirmed among 42,205 TB registered cases in 2011, and thus HIV prevalence among those with TB was $5.6 \%(2351 / 42,205)$; a total of 2579.7 years was provided for the TBC group at the follow-up assessment, 4872.8 years for the TBCR group, and 913.5 years for the TBFMA group over the 60-month follow-up period (Fig. 1). The median (M) time participants were tracked at follow-up for the TBC group was 5.0 person-years (PYs), and the inter-quartile range (IQR) was 2.2-5.0; the $M$ (IQR) for TBCR and TBFMA groups was 5.0 PYs (2.1-5.0) and 1.1 (0.3-5.0), respectively (Supplemental Fig. 1). The male-tofemale ratio among participants was 1.88:1; those who reported that they were farmers $(75.1 \%)$ and were of Han ethnicity (58.2\%) were in the majority.

\section{Mortality trend, hazard risk of mortality}

In the TBC, TBCR, and TCFMA groups, the CD4 count (IQR) was 223 cells $/ \mu \mathrm{L}$ (53.0-417.0), 184 cells $/ \mu \mathrm{L}$ (56.0$367.0)$, and 105 cells $/ \mu \mathrm{L}(25.50-268.50)$, respectively. The percentage of patients by group on ART were 53.2, 53.5, and 33.3\%; and the M (IQR) of age was 45.0 (31.0$58.0), 48.0$ (32.5-62.0), and 53.0 (9.0-67.0), respectively. Finally, differences in the distributions of age, gender, ART initiation, and CD4 count were statistically significant among TBC, TBCR, and TCFMA groups (Table 1).

At the end point of the 60-month follow-up, a total of $859 \mathrm{HIV} / \mathrm{MTB}$ co-infected individuals had died, for a 


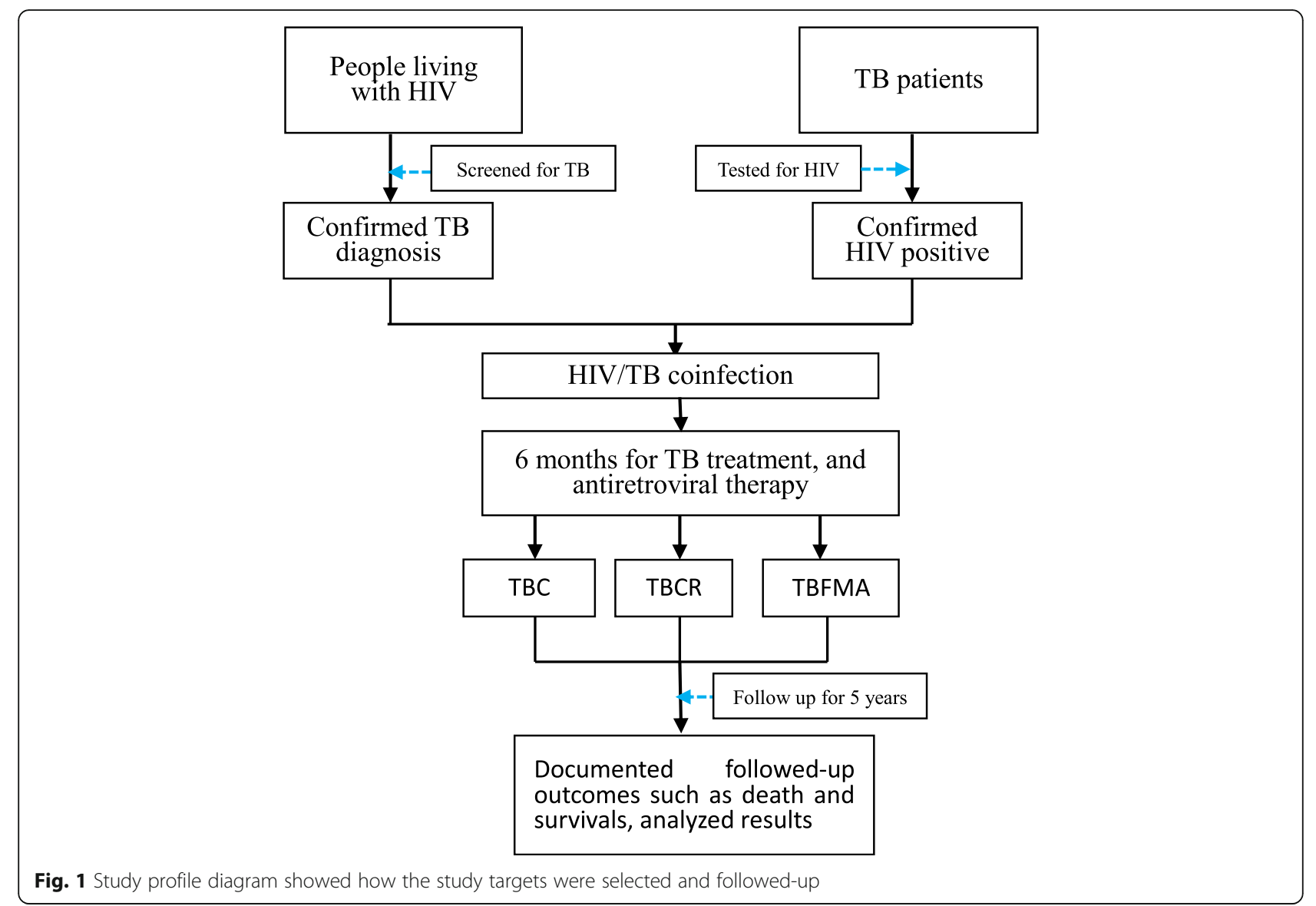

mortality of $36.5 \%$; crude mortality in TBFMA, TBRC, and TBC groups was $60.0 \%$ (229/382), 32.0\% (413/1289), and $31.9 \%(217 / 680)$. Compared to the TBC group $\left(\chi^{2}=\right.$ 78.9, $P<0.0001)$ and TBCR group $\left(\chi^{2}=97.0, P<0.0001\right)$, the crude mortality in the TBFMA group was significantly higher (see Table 2). In the initial 6 months of anti-tubercular treatment, mortality in the TBFMA group was $41.1 \%$ (157/382), while mortality in TBC and TBCR groups was $12.5 \%(85 / 680)$ and $11.6 \%(150 / 1289)$. There was no statistically significant difference between mortality in TBC and TBCR groups, whether at the 6month or 60 -month observation $\left(X_{6 m}^{2}=0.60, P=0.44\right.$; $\left.X^{2}{ }_{60 m}=0.003, P=0.95\right)$ (Table 2). However, the initial 6month mortality in the TBFMA group was significantly higher than in TBC and TBCR groups $\left(\chi^{2}=118.9, P<\right.$ 0.0001). As mortality was calculated by PYs, a declining trend was observed among all groups from 6-month to 60-month, mortality in those with TBFMA was significant higher than it was with TBC and TBCR at all timepoints (Fig. 2) (Supplemental Fig. 2).

Mortality density analysis showed that the majority of mortality in the TBFMA group occurred during the first 6 months and mortality density was higher than those in TBC and TBCR group during the same period. On the contrary, the majority of mortality in both $\mathrm{TBC}$ and
TBCR groups happened in the last year of follow-up (Fig. 3).

The HR value of mortality was calculated for TBC, TBCR, and TBFMA groups using Cox regression models. At the 60-month follow-up, the crude HR of mortality in the TBFMA group was 2.5 (95\% CI: 2.13.1) times higher than that of the TBC group, and 2.6 (95\% CI: 2.2-3.0) times higher than that of the TBCR group. A Wald chi-square test showed that the HR for mortality in the TBFMA group was significantly higher than those in the TBC and TBCR groups $\left(\chi_{\text {cure }}^{2}=95.4\right.$, $\left.P<0.0001 ; X_{\text {comp }}^{2}=131.8, P<0.0001\right)$.

\section{HR adjusted by stratification variables}

We adjusted the HR by deleting those who died within the initial 6 months of the study. The adjusted HR of mortality in the TBFMA group was 1.6 (95\% CI: $1.2-$ 2.0) times higher than the TBC group and 1.3 (95\% CI: 1.0-1.7) times higher than the TBCR group, while the adjusted HR of the TBFMA group was significantly higher than the HR of TBC and TBCR groups $\left(\chi_{\text {cure }}^{2}=\right.$ 9.95, $P=0.0002 ; X_{\text {comp }}^{2}=5.1, P=0.024$ ) (Fig. 4-1, 4-2).

Based upon preliminary analyses (see Table 1), ART, gender, age, occupation, and CD4 count were selected to 
Table 1 Demographic characteristics of HIV/MTB co-infection patients by treatment outcomes in Guangxi, Southern China

\begin{tabular}{|c|c|c|c|c|}
\hline Characteristics & TB cure $n(\%)$ & $\begin{array}{l}\text { TB complete } \\
\text { treatment } \mathrm{n}(\%)\end{array}$ & $\begin{array}{l}\text { TB treatment failure, patient } \\
\text { missing, adverse events } \mathrm{n}(\%)\end{array}$ & $P$ value \\
\hline All patients & $680(28.92)$ & $1289(54.83)$ & $382(16.25)$ & \\
\hline \multicolumn{5}{|l|}{ Age (year) } \\
\hline Median & 45.00 & 48.00 & 53.00 & $<0.0001$ \\
\hline $\mathbb{I R Q}$ & $31.00-58.00$ & $32.50-62.00$ & $39.00-67.00$ & \\
\hline Gender & & & & $<0.0001$ \\
\hline Male & $455(66.91)$ & $796(61.75)$ & $284(74.35)$ & \\
\hline Female & $225(33.09)$ & $493(38.25)$ & $98(25.65)$ & \\
\hline Ethnicity & & & & 0.30 \\
\hline Han & $403(59.26)$ & $734(56.95)$ & $231(60.47)$ & \\
\hline Zhuang & $253(37.22)$ & $523(40.57)$ & $136(35.60)$ & \\
\hline Yao & $12(1.76)$ & $21(1.63)$ & $10(2.62)$ & \\
\hline Others & $12(1.76)$ & $11(0.85)$ & $5(1.31)$ & \\
\hline Occupation & & & & $<0.0001$ \\
\hline Farmer & $538(79.12)$ & $929(72.07)$ & $306(80.10)$ & \\
\hline Government employee & $19(2.79)$ & $91(7.05)$ & $16(4.19)$ & \\
\hline Worker & $15(2.21)$ & $38(2.95)$ & $9(2.36)$ & \\
\hline House nursing & $44(6.47)$ & $74(5.74)$ & $29(7.59)$ & \\
\hline Farmer worker & $21(3.09)$ & $25(1.94)$ & $4(1.05)$ & \\
\hline Student & $12(1.76)$ & $31(2.40)$ & $0(0.00)$ & \\
\hline Others & $31(4.56)$ & $101(7.85)$ & $18(4.71)$ & \\
\hline Infection route & & & & 0.73 \\
\hline Heterosexual & $547(80.44)$ & $1004(77.89)$ & $282(73.82)$ & \\
\hline Homosexual & $11(1.62)$ & $22(1.71)$ & $3(0.79)$ & \\
\hline IDU & $35(5.15)$ & $61(4.73)$ & $14(3.66)$ & \\
\hline Blood transfusion & $13(1.91)$ & $17(1.32)$ & $3(0.79)$ & \\
\hline Others & $74(10.88)$ & $185(134.35)$ & $80(20.94)$ & \\
\hline ART & & & & $<0.0001$ \\
\hline Initiated ART & 362 (53.24) & 689 (53.45) & 127 (33.25) & \\
\hline ART naïve & 255 (37.50) & 450 (34.91) & $182(47.64)$ & \\
\hline Unknown & $63(9.26)$ & $150(11.64)$ & $73(19.11)$ & \\
\hline \multicolumn{5}{|l|}{ CD4 Count } \\
\hline Median & 223 & 184 & 105 & 0.002 \\
\hline IRQ & $53.0-417.0$ & $56.0-367.0$ & $25.50-268.50$ & \\
\hline
\end{tabular}

Abbreviation: IRQ Interquartile Range; IDU Injection drugs users; ART Antiretroviral therapy

Table 2 Crude mortality of HIV/MTB co-infection across 60 months by treatment outcomes

\begin{tabular}{|c|c|c|c|c|c|c|c|c|c|}
\hline $\begin{array}{l}\text { Treatment } \\
\text { outcomes }\end{array}$ & $\begin{array}{l}\text { Case } \\
\text { number (\%) }\end{array}$ & $\begin{array}{l}\text { Mortality in } \\
6 \text { months }(\%) \\
\end{array}$ & $\begin{array}{l}\text { Mortality in } \\
12 \text { months (\%) }\end{array}$ & $\begin{array}{l}\text { Mortality in } \\
24 \text { months (\%) }\end{array}$ & $\begin{array}{l}\text { Mortality in } \\
36 \text { months (\%) }\end{array}$ & $\begin{array}{l}\text { Mortality in } \\
48 \text { months (\%) }\end{array}$ & $\begin{array}{l}\text { Mortality in } \\
60 \text { months (\%) }\end{array}$ & $x^{2}$ & $P$ value \\
\hline $\begin{array}{l}\text { Adverse } \\
\text { events, failure, } \\
\text { missing }\end{array}$ & $382(16.25)$ & $157(41.10)$ & $187(48.95)$ & $212(55.50)$ & $222(58.12)$ & $227(59.42)$ & $229(59.95)$ & 107.8 & $<0.0001$ \\
\hline $\begin{array}{l}\text { Complete } \\
\text { treatment }\end{array}$ & $1289(54.83)$ & $150(11.64)$ & $242(18.77)$ & $315(24.44)$ & 379 (29.4) & $404(31.34)$ & 413 (32.04) & - & - \\
\hline Cure & $680(28.92)$ & 85 (12.50) & $126(18.53)$ & $164(24.12)$ & $192(28.24)$ & 206 (30.29) & 217 (31.91) & - & - \\
\hline
\end{tabular}

Abbreviation: IRQ Interquartile Range; IDU Injection drugs users; ART Antiretroviral therapy 


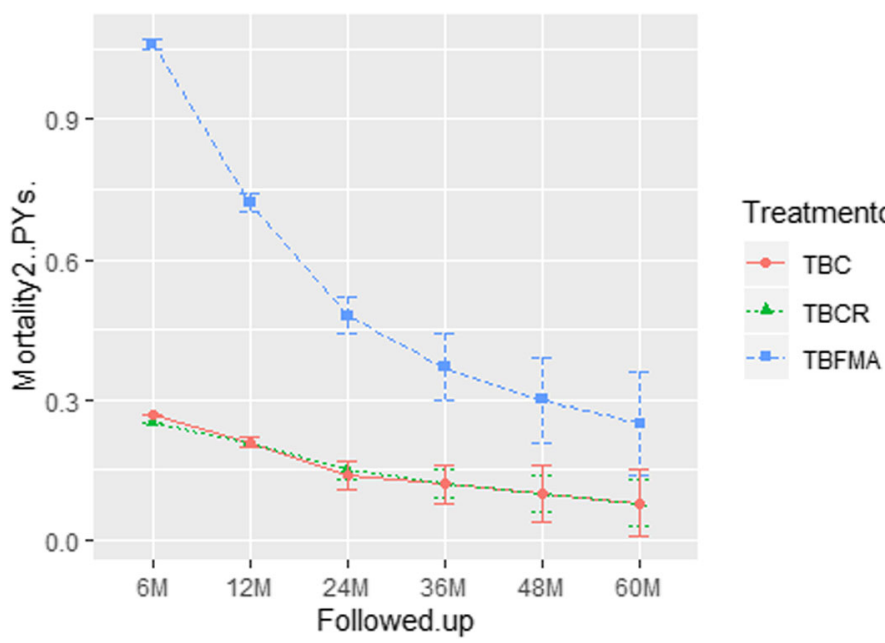

Fig. 2 Mean mortality with $\pm 95 \%$ confidence interval $(\mathrm{Cl})$ for person years of followed-up at the end of TB treatment (6 M), post-treatment year 1 (12 M), post-treatment year $2(24 \mathrm{M})$, post-treatment year $3(36 \mathrm{M})$, post-treatment year $4(48 \mathrm{M})$, and post-treatment year 5 (60 M) among HIV/MTB coinfection patients treated with tuberculosis cure (TBC) $(n=680)$, tuberculosis complete regimen (TBCR) $(n=1289)$, and tuberculosis treatment failure, patients missing, adverse events (TBFMA) $(n=382)$ in Southern China

compare the OR values in subgroups between TBFMA and the combination of TBC and TBCR. Results indicated that these selected factors were independent and unique factors that caused significant mortality across all groups except the group with CD4 count $\leq 200 \mu \mathrm{L}$ (OR = 1.5, 95\% CI:0.8-3.1, $\left.\chi^{2}=1.36, P=0.24\right)$. Mantel-Haenszel stratified analysis results showed that TBFMA among males $(\mathrm{OR}=3.9,95 \% \mathrm{CI}: 3.0-5.1)$, those $<50$ years old $(\mathrm{OR}=3.5,95 \% \mathrm{CI}: 2.5-4.9)$, and with CD4 count $>200 \mu \mathrm{L}$ $(\mathrm{OR}=3.4,95 \% \mathrm{CI}: 2.6-4.6)$ were the top three hazard risks for death, compared to the HR of these subgroups in the control group (Table 3, Fig. 4-3, 4-4).

\section{Discussion}

We found that the HIV prevalence among those first diagnosed with TB in Guangxi, China in 2011 was 5.6\% with a cross-registration-system check and imputation method. This rate was higher than in previous studies based on surveys in hospitalization and routine TB surveillance $[9,12]$, There were $24,849(58.8 \%)$ TB cases that had a documented HIV test in 2011 and the proportion of TB patients testing HIV-positive was 9.5\% $(2351 / 24,849)$, the percentage of those co-infected with HIV and TB in this study is consistent with testing results globally in 2017, but the proportion of TB patients

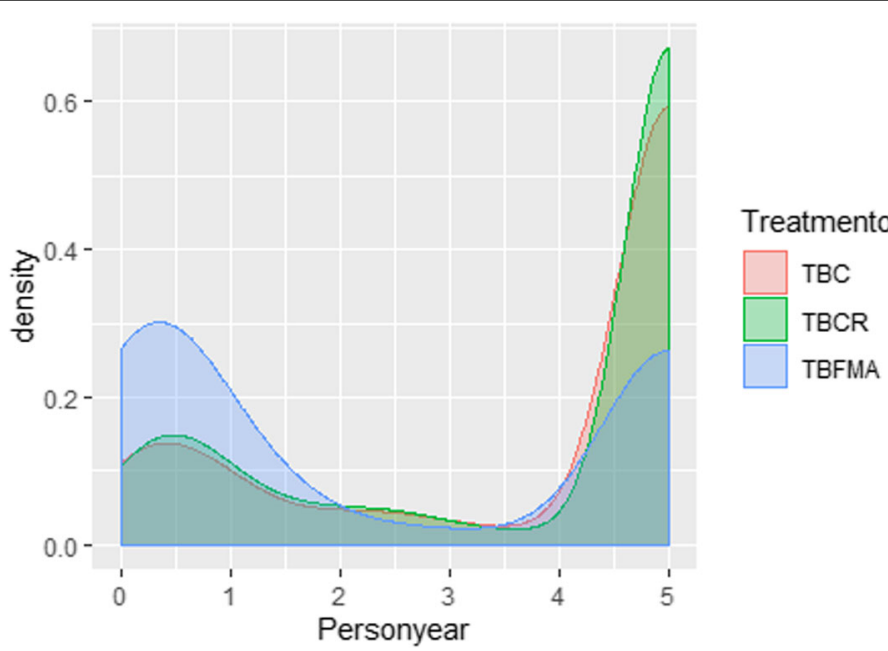

Fig. 3 Density of mortality at the end of TB treatment (0.5 PYs), post-treatment year 1 (1 PYs), post-treatment year 2 (2 PYs), post-treatment year 3 (3 PYs), post-treatment year 4 (4 PYs), and post-treatment year 5 (5 PYs) among HIV/MTB coinfection patients treated with tuberculosis cure (TBC) ( $n=680)$, tuberculosis complete regimen (TBCR) $(n=1289)$, and tuberculosis treatment failure, patients missing, adverse events (TBFMA) $(n=382)$ in Southern China 


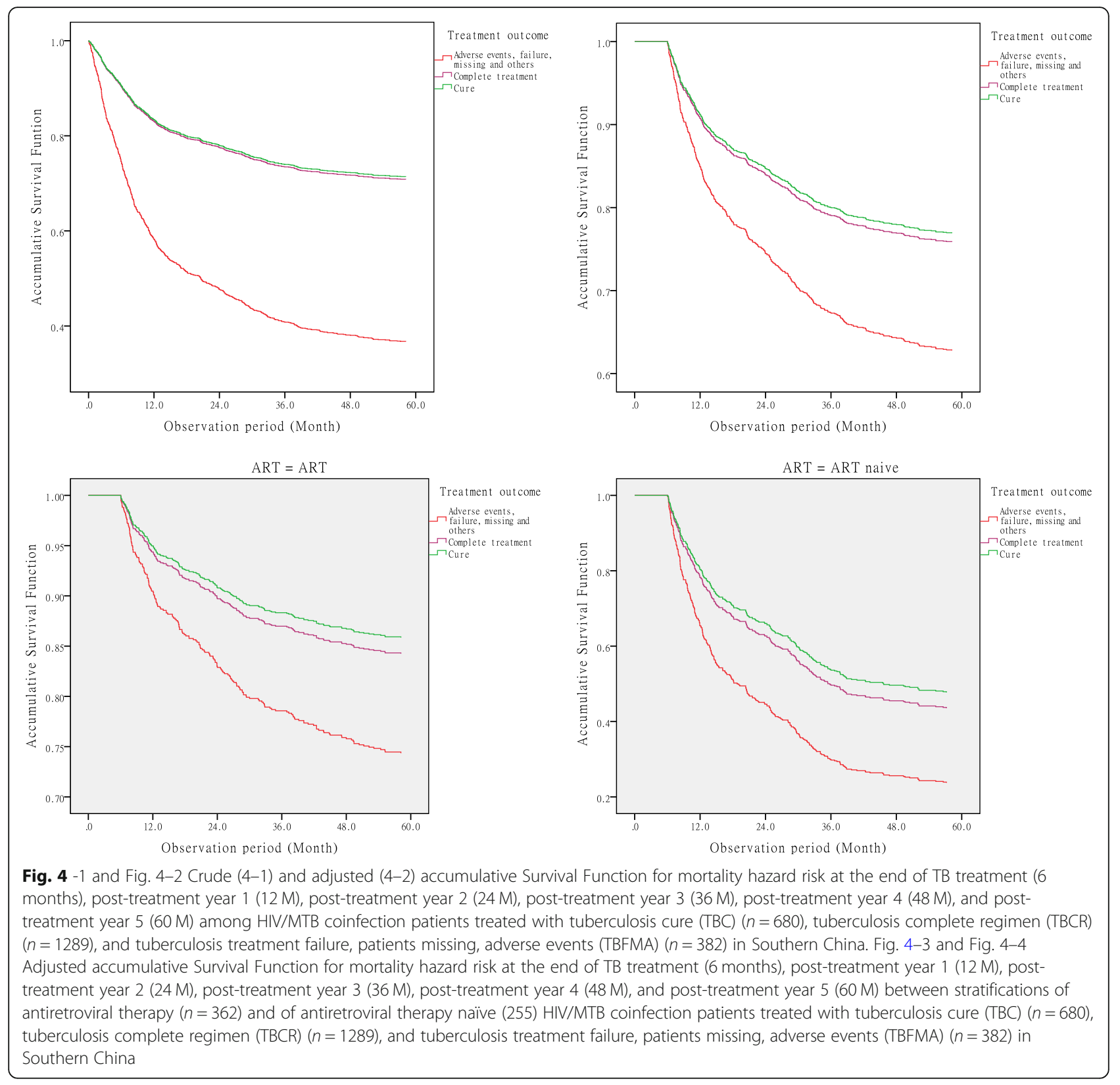

testing HIV-positive in this study was less than the WHO estimate of $15 \%$ positive in 2017 [1].

Over 850 patients in this study died over the 5-year follow-up period. The survival of HIV/MTB patients may be impacted by the degree and timing of appropriate ART and anti-tubercular therapy. As previous studies have shown that ART improves the survival rate by at least 50\% in individuals with HIV/MTB [13, 14], in 2012 the WHO endorsed a strategy recommending that ART should be initiated as early as possible for HIV-positive TB patients. Insufficient anti-tubercular therapy in HIV/ MTB led to the inability to control mycobacterial infection and high mortality [15]. Our study found that inadequate TB therapy (TBFMA) was associated with a 2.97 (95\% CI: 2.45-3.61) times higher mortality than those who were cured and a 2.91 (95\% CI: 2.46-3.43) times higher mortality than for those who completed their TB regimen during the 60-month follow-up. Those HIV and TB coinfection patients with insufficient TB treatment were likely to die in an earlier stage of followup. Even after removing those who died during the 6month duration of anti-tubercular therapy, a significant difference in mortality remained. After adjusting for those who were on ART, the OR was still 2.84 (95\% CI: 1.99-4.05) times higher among those who TB treatment failed, missing, or experienced adverse events than in 
Table 3 Cox regression on Mortality risk of HIV/MTB co-infection in different stratification by TB treatment outcome

\begin{tabular}{|c|c|c|c|c|c|c|c|c|c|c|}
\hline \multirow[t]{2}{*}{ Stratification } & \multirow{2}{*}{$\begin{array}{l}\text { TB Treatment } \\
\text { outcome }\end{array}$} & \multirow[t]{2}{*}{$\beta$} & \multirow[t]{2}{*}{ SE } & \multirow[t]{2}{*}{ Wald } & \multirow[t]{2}{*}{ df } & \multirow[t]{2}{*}{$P$ value } & \multirow[t]{2}{*}{$\operatorname{Exp}(\beta)$} & \multirow[t]{2}{*}{ 1-Exp (ß) (\%) } & \multicolumn{2}{|c|}{ 95.0\% $\operatorname{Exp}(\beta)$ Confidential Interva } \\
\hline & & & & & & & & & lower limit & Upper limit \\
\hline \multirow[t]{3}{*}{$\begin{array}{l}\text { ART and } \\
\text { ART naïve }\end{array}$} & $\begin{array}{l}\text { Adverse events, } \\
\text { failure, missing }\end{array}$ & & & 26.19 & 2.00 & $<0.0001$ & & & & \\
\hline & $\begin{array}{l}\text { Complete } \\
\text { treatment }\end{array}$ & -.548 & 0.12 & 20.00 & 1.00 & $<0.0001$ & 0.58 & 42.18 & 0.45 & 0.74 \\
\hline & Cure & -.665 & 0.14 & 23.75 & 1.00 & $<0.0001$ & 0.51 & 48.55 & 0.39 & 0.67 \\
\hline \multirow[t]{3}{*}{ Gender } & $\begin{array}{l}\text { Adverse events, } \\
\text { failure, missing }\end{array}$ & & & 21.38 & 2.00 & $<0.0001$ & & & & \\
\hline & $\begin{array}{l}\text { Complete } \\
\text { treatment }\end{array}$ & -.521 & 0.12 & 18.16 & 1.00 & $<0.0001$ & 0.59 & 40.63 & 0.47 & 0.75 \\
\hline & Cure & -.575 & 0.14 & 17.83 & 1.00 & $<0.0001$ & 0.56 & 43.70 & 0.43 & 0.74 \\
\hline \multirow[t]{3}{*}{ Age group } & $\begin{array}{l}\text { Adverse events, } \\
\text { failure, missing }\end{array}$ & & & 14.49 & 2.00 & 0.0007 & & & & \\
\hline & $\begin{array}{l}\text { Complete } \\
\text { treatment }\end{array}$ & -.449 & 0.12 & 13.23 & 1.00 & 0.0003 & 0.64 & 36.17 & 0.50 & 0.81 \\
\hline & Cure & -.458 & 0.14 & 11.02 & 1.00 & 0.0009 & 0.63 & 36.75 & 0.48 & 0.83 \\
\hline \multirow[t]{3}{*}{ CD4 group } & $\begin{array}{l}\text { Adverse events, } \\
\text { failure, missing }\end{array}$ & & & 17.87 & 2.00 & 0.0001 & & & & \\
\hline & Complete treatment & -.486 & 0.13 & 14.35 & 1.00 & 0.0002 & 0.62 & 38.47 & 0.48 & 0.79 \\
\hline & Cure & -.567 & 0.14 & 16.07 & 1.00 & 0.0001 & 0.57 & 43.28 & 0.43 & 0.75 \\
\hline
\end{tabular}

those who cured or completed TB treatment. This demonstrates that inadequate anti-tubercular therapy plays an important role in death for those with HIV/MTB coinfection. Similar results have observed in South Africa and Cote d'Ivoire [16, 17]. The reasons for high mortality in those whose TB treatment failed, missing, or experienced adverse events may due to MTB dissemination, overwhelming infections, or failure to achieve rapid immunological recovery $[18,19]$, but we did not have access to such clinical indicators in this study. Future research should focus on the relationship between immune recovery and treatment outcomes concerning HIV/MTB co-infection.

Risk factors for mortality among those HIV/MTB coinfected in China have addressed elsewhere [20, 21]. The majority of factors identified by hierarchical analysis in our study are consistent with the findings of previous studies. Adjusted by these risk factors, the HR for those whose treatment failed was still significantly higher than those who completed treatment and those who were cured. These results underline that uncontrolled TB with insufficient treatment should be considered as a leading cause of mortality among those with HIV/MTB coinfection. According to the $\mathrm{WHO} \mathrm{TB}$ treatment guidelines [22], the standard treatment duration for cases of drugsusceptible TB is 6 months, and treatment for drugresistant TB is longer. However, longer treatment duration may lead to low adherence to therapy and poor compliance has been associated with failure and drugresistant TB [23-25], and lead to a high risk of medium to long term mortality. Methods to improve adherence such as shortening treatment duration, monitoring, and treatment of adverse events, and improving treatment success rates should be considered as a priority in clinical practice to reduce mortality risk of HIV/TB coinfection.

In our study, the median CD4 count found in the TBFMA group was 105 cells/ $\mu \mathrm{L}$ (IQR: 25.5-268.5). This more advanced HIV/MTB stage leads to high mortality due to the effects of immune reconstitution inflammatory syndrome (IRIS). The enhanced immune function associated with ART initiation to treat HIV/MTB can lead to worsened clinical outcomes due to the increased severity of IRIS. TB-IRIS can categorize as "paradoxical" or "unmasking" in the mechanism. In paradoxical TBIRIS, ART initiated in a patient with known TB, and clinical TB symptoms worsen after ART initiation. In unmasking TB-IRIS, patients with previously undiagnosed and untreated TB, such as latent TB, present with inflammatory features of TB after ART initiation [26]. Studies have shown that those with an advanced stage of HIV/MTB at the time of ART initiation, and the initiation of ART closer to the time of TB treatment initiated were consistent risk factors for TB IRIS [27, 28]; other research has found that the development of TB IRIS is associated with the rapid expansion of pathogen-specific CD4 cells following ART initiation [29, 30]. However, the results of other research are not consistent [31]. Our study cannot provide more details on TB IRIS because of the manner of data collection; thus, more research on 
pathophysiology and immunology are needed to define more precisely the mechanisms of TB-IRIS.

A strength of our study is that our results provide direct evidence for policymakers and stakeholders to highlight practical therapeutic developments and to review clinical outcomes of TB treatment for HIV/MTB co-infection. However, there were limitations to this study. First, we could not stratify data into pulmonary and extra-pulmonary $\mathrm{TB}$ to determine more precisely the impact of different TB types. Second, we could not analyze the role of TB IRIS on the mortality of HIV/ MTB co-infection because of the method of data collection.

\section{Conclusions}

HIV prevalence in TB registrations was $5.57 \%$ in Southern China; insufficient TB treatment increased long-term mortality nearly three times higher than those who were cured of $\mathrm{TB}$ and those who completed their $\mathrm{TB}$ regimen, the majority of the individuals who had inadequate TB treatment were likely to die in the 6 months of the follow-up period. The findings emphasize that sufficient TB treatment should be provided, the treatment success rates of TB treatment should be scaled up, and efforts toward early TB case-finding among people living with HIV should increase.

\section{Supplementary information}

Supplementary information accompanies this paper at https://doi.org/10. 1186/s12879-020-05527-0.

Additional file 1 Supplemental Fig. 1. Box plot with mean person year (white rhombus in charts), median person years (black line in charts) of followed-up among HIV/MTB coinfection patients treated with tuberculosis cure (TBC) $(n=680)$, tuberculosis complete regimen (TBCR) $(n=$ 1289), and tuberculosis treatment failure, patients missing, adverse events (TBFMA) $(n=382)$ in Southern China. Supplemental Fig. 2. Mortality trend for percentage at the end of TB treatment ( 6 months), posttreatment year $1(12 \mathrm{M})$, post-treatment year $2(24 \mathrm{M})$, post-treatment year $3(36 \mathrm{M})$, post-treatment year $4(48 \mathrm{M})$, and post-treatment year $5(60 \mathrm{M})$ among HIV/MTB coinfection patients treated with tuberculosis cure (TBC) ( $n=680)$, tuberculosis complete regimen (TBCR) $(n=1289)$, and tuberculosis treatment failure, patients missing, adverse events (TBFMA) $(n=382)$ in Southern China.

\section{Abbreviations}

IRQ: Interquartile range; IDU: Injection drugs users; ART: Antiretroviral therapy; M: Median

\section{Acknowledgements}

The authors would like to thank the staff who work in the Division of HIV/TB Coinfection Treatment, the Fourth People Hospital of Nanning City to extract the data from a local HIV/TB treatment cohort.

\section{Authors' contributions}

ZX and ZZ2 conducted sample collections. HL made substantial contributions to the conception and design of the work. JL and CZ contribute to the analysis of the data and literature review as well. ZZ1 and EN made major contributions to the interpretation and manuscript preparation. EN substantively revised the work/manuscript. All authors have approved the submitted version.

\section{Funding}

This work was supported by: 1. The National Nature Science Foundation of China (No. 81760618); 2. Expanded and Applied Project of Appropriate Technology of Medicine and Health in Guangxi (No. S201682).

\section{Availability of data and materials}

All data generated or analyzed during this study are included in this published article (and its supplementary information files).

\section{Ethics approval and consent to participate}

Cohort data were extracted from the China National HIV and TB Program registration databases and analyzed retrospectively and anonymously. Informed consent forms were also signed by patients before they were tested for HIV or screened for TB. Written data use consent forms were signed by patients from the beginning of confirmation of HIV positive status.

\section{Consent for publication}

Yes.

\section{Competing interests}

The authors declare that they have no competing interests.

\section{Author details}

1 Department of Epidemiology and Statistic, School of Public Health, Guangxi Medical University, Nanning 530021, Guangxi, China. ${ }^{2}$ AIDS Program, Guangxi Zhuang Autonomous Region Center for Disease Control and Prevention, 18 Jin Zhou Road, Nanning 530028, China. ${ }^{3}$ Department of Behavioral Sciences and Health Education, Rollins School of Public Health, Emory University, Atlanta 30322, GA, U.S.A.. ${ }^{4}$ HIV/TB Treatment Department, the Fourth Hospital of Nanning City, Nanning 530023, China. ${ }^{5}$ Guangxi Key Laboratory of AIDS Prevention and Treatment, School of Public Health, Guangxi Medical University, Nanning 530021, Guangxi, China. ${ }^{6}$ Guangxi Collaborative Innovation Center for Biomedicine, Life Sciences Institute, Guangxi Medical University, No.22, Shuangyong Road, Qingxiu District, Nanning 530021, Guangxi, China.

Received: 29 April 2020 Accepted: 19 October 2020

Published online: 23 November 2020

\section{References}

1. World Health Organization. Global tuberculosis report 2017. Geneva: World Health Organization; 2017. (DB/OL). License: CC BY-NCSA 3.0 IGO. (http:// www.who.int/tb/publications/global_report/en/)

2. World Health Organization. Global tuberculosis report 2015. Geneva: World Health Organization; 2015. (DB/OL).

3. Selwyn PA, Hartel D, Lewis VA, Schoenbaum EE, Vermund SH, Klein RS, et al. A prospective study of the risk of tuberculosis among intravenous drug users with human immunodeficiency virus infection. N Engl J Med. 1989; 320:545. https://doi.org/10.1056/NEJM198903023200901.

4. Corbett EL, Charalambous S, Moloi VM, Fielding K, Grant AD, Dye C, et al. Human immunodeficiency virus and the prevalence of undiagnosed tuberculosis in African gold miners. Am J Respir Crit Care Med. 2004;170: 673. https://doi.org/10.1164/rccm.200405-5900C.

5. López-Gatell H, Cole SR, Hessol NA, French AL, Greenblatt RM, Landesman S, et al. Effect of tuberculosis on the survival of women infected with human immunodeficiency virus. Am J Epidemiol. 2007;165:1134. https://doi.org/10. 1093/aje/kwk116.

6. Badri M, Ehrlich R, Wood R, Pulerwitz T, Maartens G. Association between tuberculosis and HIV disease progression in a high tuberculosis prevalence area. Int J Tuberc Lung Dis. 2001;5:225. 11326821.

7. WHO HIV/AIDS Programme. Antiretroviral therapy for HIV infection adults and adolescents: recommendations for a public health approach (2010 revision) [R]. 2010. 21-24.

8. Ravimohan S, Tamuhla N, Steenhoff AP, Letlhogile R, Makutu DK, Nfanyana $K$, et al. Early immunologic failure is associated with early mortality among advanced HIV-infected adults initiating antiretroviral therapy with active tuberculosis. J Infect Dis. 2013;208:1784-93.

9. Gao L, Zhou F, Li X, Jin Q. HIV/TB co-infection in mainland China: a metaanalysis. PLoS One 2010;5(5): e10736. https://doi.org/https://doi.org/10.1371/ journal.pone.0010736. Doi: 10.1371/journal. pone.0064915. 
10. Ji Y, Wang Z, Shen J, Chen J, Yang J, Qi T, et al. Trends and characteristics of all-cause mortality among HIV-infected inpatients during the HAART era (2006-2015) in Shanghai, China. Biosci Trends. 2017;11(1):62-68. https://doi. org/https://doi.org/10.5582/bst.2016.01195.

11. Zheng ZG, Geng WK, Lu ZZ, Li JJ, Zhou CX, Yang WM. Impact on mortality of human immunodeficiency virus and Mycobacterium tuberculosis coinfection, Guangxi Zhuang Autonomous Region, 2011. Chin J Epidemiol, 2018;39(2):124-127. https://doi. org/https://doi.org/10.5582/bst.2016.01195.

12. Lawn SD, Kranzer K, Edwards DJ, McNally M, Bekker LG, Wood R. Tuberculosis during the first year of antiretroviral therapy in a south African cohort using an intensive pretreatment screening strategy [J]. AIDS. 2010; 24(9):1323-8.

13. Zheng ZG, Cui ZZ, Huang MY, Pan DX. Effect of antiretroviral therapy in reducing deaths among patients co-infected with Mycobacterium tuberculosis and human immunodeficiency virus in Guangxi. Chin J Epidemiol. 2015;36(2):124-127. https://DOl:10.3760/ cma.j.issn. 0254-6450. 2015.02.005.

14. Jouanguy E, Lamhamedi-Cherradi S, Altare F, Fondaneche MC, Tuerlinckx D, Blanche $\mathrm{S}$, et al. Partial interferon gamma receptor 1 deficiency in a child with tuberculoid bacillus Calmette-Guerin infection and a sibling with clinical tuberculosis. J Clin Invest 1997;100:2658-2664. [PubMed: 9389728].

15. Wong EB, Omar T, Setlhako GJ, Osih R, Feldman C, Murdoch DM, et al. Causes of death on antiretroviral therapy: a post-mortem study from South Africa. PLoS One. 2012;7:e47542.

16. Greenberg AE, Lucas S, Tossou O, Coulibaly IM, Coulibaly D, Kassim S, Ackah A, et al. Autopsy-proven causes of death in HIV-infected patients treated for tuberculosis in Abidjan, Cote d'Ivoire, AIDS 1995;9:1251-1254. [PubMed: 8561978].

17. Holmes CB, Wood R, Badri M, Zilber S, Wang B, Maartens G, et al. CD4 decline and incidence of opportunistic infections in Cape Town, South Africa: implications for prophylaxis and treatment. J Acquir Immune Defic Syndr 2006;42:464-469. [PubMed: 16810113].

18. Day $C L$, Abrahams DA, Lerumo L, Janse van Rensburg E, Stone L, O'Rie T, et al. Functional capacity of Mycobacterium tuberculosis-specific T cell responses in humans is associated with mycobacterial load J Immunol 2011; 187:2222-2232. [PubMed: 21775682].

19. Zheng ZG, Tang ZZ, Lu QL, Wei H, Geng WK. Influential factors analysis on the survival time of patients infected with tuberculosis and HIV. Chin J Prev Med 2015;49(10):907-913, https://DOl: 10.3760/cma.j.issn.0253-9624.2015.10. 014.

20. Ji YJ, Liang PP, Shen JY, Sun JJ, Yang JY, Chen J, et al. Risk factors affecting the mortality of HIV infected patients with pulmonary tuberculosis in the CART era: a retrospective cohort study in China. Infect Dis Poverty. 2018;7:25. https://doi.org/10.1186/s40249-018-0405-8.

21. Meintjes G, Lawn SD, Scano F, Maartens G, French MA, Worodria W, et al. Tuberculosis-associated immune reconstitution inflammatory syndrome: case definitions for use in resource-limited settings. Lancet Infect Dis. 2008; 8:516-23. https://doi.org/10.1016/S1473-3099(08)70184-1.

22. WHO. Treatment of Tuberculosis: Guidelines, Fourth Edition. 4th ed. 2010.

23. Sharma SK, Turaga KK, Balamurugan A, Saha PK, Pandey RM, Jain NK, et al. Clinical and genetic risk factors for the development of multi-drug resistant tuberculosis in non-HIV infected patients at a tertiary care center in India: A case-control study. Infect Genet Evol. 2003; 3: 183-188. doi: https://doi.org/ 10.1016/S1567-1348(03)00086-8 PMID: 14522182.

24. Gelmanova IY, Keshavjee S, Golubchikova VT, Berezina VI, Strelis AK, Yanova GV, et al. Barriers to successful tuberculosis treatment in Tomsk, Russian Federation: non-adherence, default and the acquisition of multidrug resistance. Bull World Heal Organ. 2007;85:703-11. https://doi.org/10.2471/ BLT.06.038331.

25. Saunders NJ, Trivedi UH, Thomson ML, Doig C, Laurenson IF, Blaxter ML. Deep resequencing of serial sputum isolates of mycobacterium tuberculosis during therapeutic failure due to poor compliance reveals stepwise mutation of key resistance genes on an otherwise stable genetic background. J Infect. 2011;62:212-7. https://doi.org/10.1016/j.jinf.2011.01.003.

26. Naidoo K, Yende-Zuma N, Padayatchi N, Jithoo N, Nair G, Bamber S, Gengiah S, et al. The immune reconstitution inflammatory syndrome after antiretroviral therapy initiation in patients with tuberculosis: findings from the SAPiT trial. Ann Intern Med 2012;157:313-324. [PubMed: 22944873].

27. Laureillard D, Marcy O, Madec Y, Chea S, Chan S, Borand L, et al. Paradoxical tuberculosis associated immune reconstitution inflammatory syndrome after early initiation of antiretroviral therapy in a randomized clinical trial. AIDS 2013;27:2577-2586. [PubMed: 24096631].

28. Luetkemeyer AF, Kendall MA, Nyirenda M, Wu X, Ive P, Benson CA, et al. Tuberculosis immune reconstitution inflammatory syndrome in A5221 STRI DE: timing, severity and implications for HIV-TB programs. J Acquir Immune Defic Syndr. 2014 Apr 1;65(4):423-8. https://doi.org/10.1097/QAI. 0000000000000030.

29. Bourgarit A, Carcelain G, Martinez V, Lascoux C, Delcey V, Gicquel B, et al. Explosion of tuberculin-specific Th1-responses induces immune restoration syndrome in tuberculosis and HIV co-infected patients. AIDS 2006;20:F1-F7. [PubMed:16511406].

30. Bourgarit A, Carcelain G, Samri A, Parizot C, Lafaurie M, Abgrall S, et al. Tuberculosis-associated immune restoration syndrome in HIV-1-infected patients involves tuberculin-specific CD4 Th1 cells and KIR-negative gamma delta T cells. J Immunol 2009;183:3915-3923. [PubMed: 19726768].

31. Meintjes G, Wilkinson KA, Rangaka MX, Skolimowska K, van Veen K, Abrahams M, et al. Type 1 helper T cells and FoxP3-positive T cells in HIVtuberculosis-associated immune reconstitution inflammatory syndrome. Am J Respir Crit Care Med 2008;178:1083-1089. [PubMed: 18755923].

\section{Publisher's Note}

Springer Nature remains neutral with regard to jurisdictional claims in published maps and institutional affiliations.
Ready to submit your research? Choose BMC and benefit from:

- fast, convenient online submission

- thorough peer review by experienced researchers in your field

- rapid publication on acceptance

- support for research data, including large and complex data types

- gold Open Access which fosters wider collaboration and increased citations

- maximum visibility for your research: over $100 \mathrm{M}$ website views per year

At BMC, research is always in progress.

Learn more biomedcentral.com/submissions 